\title{
Immune responses in rapidly progressive dementia: a comparative study of neuroinflammatory markers in Creutzfeldt-Jakob disease, Alzheimer's disease and multiple sclerosis
}

\author{
Katharina Stoeck ${ }^{\dagger}$, Matthias Schmitz ${ }^{*}$, Elisabeth Ebert, Christian Schmidt and Inga Zerr
}

\begin{abstract}
Immunological responses may contribute to disease progression and clinical heterogeneity in neurodegenerative dementia, for example, Alzheimer's disease (AD) and Creutzfeldt-Jakob disease (CJD). Recently, a rapidly progressive form of $\mathrm{AD}$ (rpAD) has been described. On neuropathological grounds classical AD and rpAD are not distinguishable at present. All those protein aggregopathies show a state of chronic inflammation with microglia activation and production of proinflammatory cytokines. In this context, it is hypothesized that the severity of the surrounding inflammation substantially contributes to disease progression and accelerated disease courses as seen in rpAD. Using a cytokine multiplex array based on Luminex Technology, we studied 17 pro- and anti-inflammatory cytokines in cerebrospinal fluid (CSF) and serum from patients with classical dementia (AD) or rapidly progressive dementia (Creutzfeldt-Jakob disease (CJD), rpAD). For controls, we chose patients with multiple sclerosis (MS) and non-neurodegenerative diseases. We found a significant and isolated elevation of proinflammatory cytokines (IL-13, TNF- $a$ and G-CSF) in the serum of rpAD patients. In CSF, IL-8 and MCP-1 chemokines were significantly elevated in CJD patients and MCP-1 in AD patients.

In conclusion, we found a characteristic proinflammatory cytokine response in the serum of rpAD patients. It might explain the more rapidly progressive course of the rpAD subform and can be helpful in distinguishing between classical $\mathrm{AD}$ and $\mathrm{rpAD}$.
\end{abstract}

\section{Introduction}

Immunological responses in neurodegenerative disease pathogenesis such as in Alzheimer's disease (AD) and Creutzfeldt-Jakob disease (CJD) have become of increasing scientific interest in the past years. Both diseases are neuropathologically characterized by the deposition of amyloid fibrils formed by amyloid beta $(A \beta)$ in $A D$, whereas in prion diseases, the depositions are formed by the abnormally folded host-derived prion protein scrapie $\left(\mathrm{PrP}^{\mathrm{Sc}}\right)$.

Since the change in the conformation seems to be the major pathogenic event, both diseases are considered as aggregational or conformational disorders.

\footnotetext{
* Correspondence: Matthias.Schmitz@med.uni-goettingen.de

${ }^{\dagger}$ Equal contributors

Department of Neurology, Clinical Dementia Centre, DZNE and National Reference Centre for Human Prion Diseases, University Medical Center Göttingen, Robert-Koch-Str.40, 37075 Göttingen, Germany
}

It has been shown that plaque formation in $\mathrm{AD}$ and CJD is influenced early by immune system responses through MHC II surface expression and complement activation, which secondarily leads to microglia recruitment and secretion of proinflammatory cytokines such as interleukin (IL)- $1 \beta$, IL-6, and tumor necrosis factor- $\alpha$ (TNF- $\alpha$ ), as well as chemokines (IL-8, macrophage inflammatory protein-1 $\beta$ (MIP-1 $\beta$ ), monocyte chemoattractant protein-1 (MCP-1) and growth factor macrophage-colony stimulating factor (MG-CSF) [1,2].Within the concept of plaque formation, the issue of whether this microglial response is purely reactive, or whether it also has causative effects, arises. Microglial-produced inflammatory mediators have neurotoxic as well as neuroprotective mechanisms. This has been shown, for example, for TNF- $\alpha$, where excess levels might cause neurotoxicity, and mild oxidative and low-dose TNF- $\alpha$ could, alternatively, trigger 
neuroprotective or anti-apoptotic pathways [3]. At later stages in the process of neurodegeneration, neuronal loss occurs due to the neurotoxic effects of proinflammatoy immune-mediating molecules [4]. However, it remains unknown whether neurons are active or passive players in the process of neuronal loss, as it has been shown that increased expression of complement factors and inducible cyclooxygenase-2 (COX-2) were mainly found in neurons and only to a minor extent in microglia cells in AD [5].

In addition, an important role of cellular prion protein $\left(\operatorname{PrP}^{C}\right)$ in modulating age-associated brain disorders such as $\mathrm{AD}$ has been described. $\operatorname{PrP}^{\mathrm{C}}$ can either regulate the amyloid beta precursor protein processing (the uptake of A 3 ) [6-8], or it may protect cells from inflammation [9]. With $\operatorname{PrP}^{\mathrm{C}}$ silencing, it has been shown that $\operatorname{PrP}^{\mathrm{C}}$ plays a role in immunological homoeostasis by regulating the $\mathrm{T}$ cell receptor-mediated $\mathrm{T}$ cell activation. This opens a novel potential target for therapeutic immunomodulation [10].

Given this background information, we hypothesized that immune response mechanisms such as microglia activation and production of proinflammatory cytokines, as well as altered levels of $\operatorname{PrP}^{\mathrm{C}}$, might trigger increases in disease severity and rapid courses as seen in rpAD and CJD in the clinical context.

CJD represents a form of a rapidly progressive dementia caused by protein misfolding. The main disease duration generally extends to 6 month [11]. However, different disease courses have been described depending on the molecular subtype, with disease durations ranging from 4 to 24 month [12].

There is also substantial heterogeneity in the clinical presentation in $\mathrm{AD}$ patients regarding disease course. In classical AD, mean disease duration of 7 years is acknowledged. However, there is a huge variety in $\mathrm{AD}$, and some patients follow a disease course up to 20 years. In the framework of our surveillance studies, a distinct subtype of $\mathrm{AD}$, rapidly progressive $\mathrm{AD}$ (rpAD) was identified. Patients with rpAD can mimic the clinical course of CJD with a progressive cognitive decline ( $>6$ mini-mental test points/year) and short disease duration ( $<2$ years, 6 to 8 months), as well as early focal neurological signs, such as the occurrence of extra-pyramidal symptoms and myoclonus. Patients with rpAD are often similar in age to CJD (age range 60 to 70 years), whereas patients with classical $\mathrm{AD}$ are often older at disease onset (age range 70 to 80 years and older) [13].

Although a commonly accepted definition of rpAD does not exist at present, this subtype is subject to present scientific work with regard to the identification of diseasemodifying factors.

In the present study we addressed the role of inflammation on the disease course in aggregational neurodegenerative diseases by investigating pro- and anti-inflammatory cytokines in cerebrospinal fluid (CSF) and serum from patients with classical $A D$, as well as patients with $\mathrm{rpAD}$ and CJD, subgroups representative of rapidly progressive dementia. Patients with multiple sclerosis (MS), the most common disease of chronic CNS inflammation that causes neurodegeneration, and non-neurological patients were included as controls.

We focused therefore on pro- and anti-inflammatory cytokine profiles that suggest a specific immune response (for example, TH1, TH2, TH17 or innate immune response). Both serum and CSF samples were analyzed in order to identify either systemic (serum) or CNS-borne (CSF) immune system changes.

\section{Methods}

\section{Patients and sample collection}

We analyzed CSF and serum samples from 12 sporadic CJD patients with various codon 129 genotypes (6 MM, $3 \mathrm{MV}$ and $3 \mathrm{VV}$; 6 female, 6 male; aged 55 to 85 years; mean age $64.5 \pm 1.5$ years), collected between 2012 and 2013. We analyzed samples from $35 \mathrm{AD}$ patients $(15$ rapidly progressive $\mathrm{AD}, 20$ classical $\mathrm{AD}$; 20 female, 15 male; aged between 60 and 85 years; mean age $69.5 \pm$ 2.5 years), collected between 2009 and 2013 and from 12 multiple sclerosis patients ( 6 female, 6 male; aged 30 to 70 years; mean age $55 \pm 4.5$ years), collected in 2012 . All samples were directly stored at $-80^{\circ} \mathrm{C}$ and repeated freezing/thawing cycles were avoided.

All patients with CJD were classified as definite cases by neuropathological examinations or as probable CJD cases according to diagnostic consensus criteria $[11,14,15]$. Classical AD patients were diagnosed according to the Dubois criteria [16]. Rapidly progressive AD patients were selected according to clinical presentation as reported previously by the German CJD surveillance group [17]. Risk factors such as homozygosity for ApoE 4, a history of brain trauma, and a current treatment with immunosuppressive drugs, as well as a state of systemic infection at the point of sample collection were excluded. MS patients were diagnosed according to McDonald criteria [18]. Patients of the control group ( 6 female, 6 male; aged 50 to 85 years; mean age $62.5 \pm 2.5$ years) were diagnosed with depression, headache, vertigo or pain syndromes. An organic disease of the central nervous system was excluded during the diagnostic workup. All collected CSF and serum samples were stored at $-80^{\circ} \mathrm{C}$ prior to analysis.

\section{Ethics}

The present study was conducted according to the revised Declaration of Helsinki and Good Clinical Practice guidelines and has been approved by the local ethics committee in Göttingen (No. 9/6/0). Informed consent was given by all study participants or their legal next of kin. All samples were anonymized. 


\section{Cytokine multiplex assay}

Cytokine levels in CSF and serum samples were measured using the Bio-Plex 200 System, which is based on Luminex xMAP Technology (Bio-Rad, Munich, Germany). In the present study, we screened CSF and serum samples using the Bio-Plex Pro human cytokine 17-plex assay, cytokine group 1 (Bio-Rad, Munich, Germany). The following cytokines were simultaneously detected (detection range is shown in parentheses): IL- $1 \beta$ (3.3 to $3,261 \mathrm{pg} / \mathrm{ml}$ ), IL2 (2.1 to $17,772 \mathrm{pg} / \mathrm{ml}), \mathrm{IL}-4$ (2.2 to $3,467 \mathrm{pg} / \mathrm{ml}), \mathrm{IL}-5$ (3.1 to $7,380 \mathrm{pg} / \mathrm{ml}$ ), IL-6 (2.3 to $18,880 \mathrm{pg} / \mathrm{ml}$ ), IL-7 (3.1 to $6,001 \mathrm{pg} / \mathrm{ml}$ ), IL-8 (1.9 to $26,403 \mathrm{pg} / \mathrm{ml}$ ), IL-10 (2.2 to $8,840 \mathrm{pg} / \mathrm{ml})$, IL-12 (p70) (3.3 to $13,099 \mathrm{pg} / \mathrm{ml})$, IL-13 (3.7 to 3,137$)$, IL-17 (4.9 to 12,235$),$ G-CSF (2.4 to 11,565), GM-CSF (63.3 to 6,039), IFN- $\gamma$ (92.6 to $52,719)$, MCP-1 (2.1 to 2,820 ) (MCAF), MIP-1 $\beta$ (2.0 to $1,726)$ and TNF- $\alpha(5.8$ to 95,484$)$.

The cytokine assay was performed according to the manufacturer's instructions. Samples were thawed on ice and mixed by vortexing and then diluted 1:4 in sample diluent buffer. The signal was detected by using the BioPlex 200 system and the Bio-Plex Manager Software version 6.0 .

\section{Determination of $A \beta 1-40$ and $A \beta 1-42$ level}

Levels of $A \beta 1-40$ were ascertained using the full-length A $\beta 1-40$ high sensitive assay ELISA obtained from IBL International (Hamburg, Germany), which had a detection range of 1.56 to $100 \mathrm{pg} / \mathrm{ml}$. Levels of $A \beta 1-42$ were determined by the use of a commercially available ELISA kit (INNOTEST ${ }^{\mathrm{TM}}$-AMYLOID (1-42), Innogenetics, Gent, Belgium) with a detection range of 125 to $2,000 \mathrm{pg} / \mathrm{ml}$.

All ELISA measurements were performed according to the protocol of the manufacturer. The colorimetric reaction was measured at $450 \mathrm{~nm}$ with a 1420 Victor2 Multilabel Counter (Wallac) (PerkinElmer, Waltham, Massachusetts, USA). Each sample was measured in duplicate. For analysis, we calculated the median.

\section{Determination of Tau and p-Tau 181 level}

CSF levels of total Tau protein were measured using a commercially available ELISA kit (INNOTEST ${ }^{\mathrm{TM}}$ hTAU $\mathrm{Ag}$, Innogenetics) with a detection range of 50 to 2,500 pg/ $\mathrm{ml}$ (detection limit: $34 \mathrm{pg} / \mathrm{ml}$ ). For the determination of Tau level, we followed the manufacturer's instructions. Human Tau, phosphorylated at Thr181 (phosphorylated Tau) was analyzed quantitatively by the use of a commercially available ELISA kit (INNOTEST ${ }^{\mathrm{Tm}}$ PHOSPHO-TAU (181 P), Innogenetics) with a detection range of 15.6 to 1,000 pg/ml (detection limit: 3 pg/ml).

Briefly, before antibody incubations, each sample $(75 \mu \mathrm{l})$ was diluted 1:1 in sample diluent. The colorimetric reaction was measured at $450 \mathrm{~nm}$ with a 1420 Victor2 Multilabel Counter (Wallac) (PerkinElmer). Each sample was measured in duplicate. For analysis, we calculated the median.

\section{Determination of prion protein level}

To determine the prion protein $(\mathrm{PrP})$ concentration, we used a commercial BetaPrion BSE-ELISA Test Kit (AJ Roboscreen, Leipzig, Germany) and omitted the PK digestion step. We followed a slightly modified protocol as reported earlier $[19,20]$. Our aim was to measure the concentration of total PrP in CSF and serum. Samples were diluted and measured according to the manufacturer's instruction. To confirm the results, a statistically robust number of samples were analyzed by an additional XMAP-based assay for PrP, which has already been published [19]. All chemicals and equipment were obtained from (Bio-Rad). The detection range was from $6.25 \mathrm{ng} /$ $\mathrm{ml}$ to $500 \mathrm{ng} / \mathrm{ml}$.

\section{Statistical analysis}

Statistical evaluation of the data was performed using STATISTICA for Windows version 10 (Stat Soft, Inc.). To determine the statistical significance, we used the nonparametric Kruskal-Wallis test. The statistical analysis was shown for each patient group [see Additional file 1]. Differences were considered significant at an error probability of $P<0.05$.

\section{Results}

Levels of proinflammatory cytokines were increased in the serum of patients who had a rapidly progressive form of Alzheimer's disease

The levels of a cytokine panel, consisting of 17 different cytokines, were measured in serum samples from CJD, $\mathrm{MS}, \mathrm{AD}, \mathrm{rpAD}$ and control patients using the Bio-Plex Pro human cytokine 17-plex assay. As a major finding we observed significantly elevated concentrations of proinflammatory cytokines (IL-13, TNF- $\alpha$ and G-CSF) in serum of patients with rpAD compared to AD, CJD, MS and control patients. Furthermore, the level of IL-6 was significantly increased in rpAD cases compared to MS patients, while determination of IL-7 level showed a slight increase (not significant) in rpAD patients (Figure 1A-E). The immune response profile was reflected both by $\mathrm{TH} 1 /$ TH17 (IL-6, IL7 and TNF- $\alpha$ ) and TH2-associated cytokines (IL-13 and G-CSF).

The expression of IL-1 $\beta$, IL-2, IL-4, IL-5, IL-8, IL-10, IL-12 (p70), IL-17, GM-CSF, IFN- $\gamma$, MCP-1 and MIP-1 $\beta$ was either not measurable or not significantly changed in serum of our patient cohort (data not shown). Additionally, we observed no significant variation in levels of $\operatorname{PrP}^{C}$ between rpAD, AD, MS, CJD patients and controls in either the serum (Figure 1F) or the CSF (Figure 2C). 
A

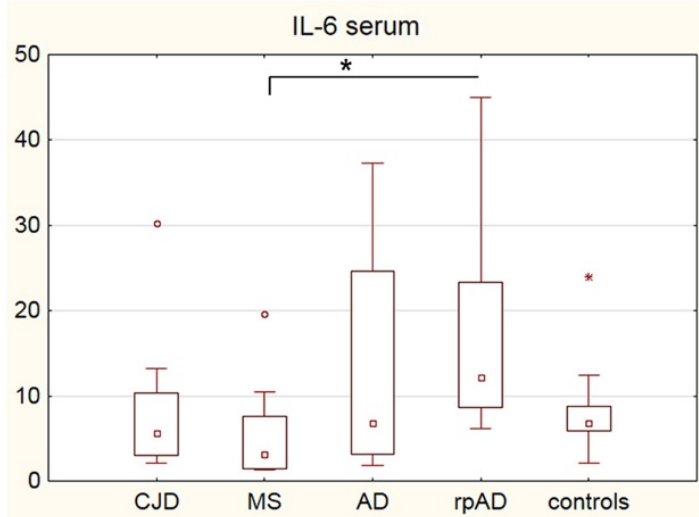

C

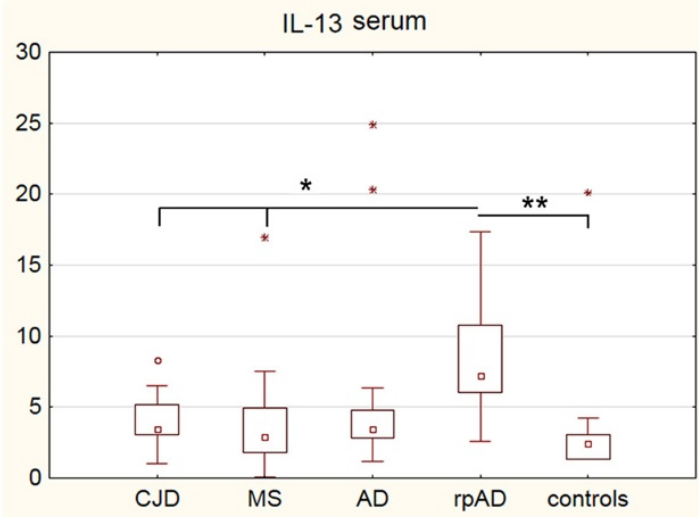

E

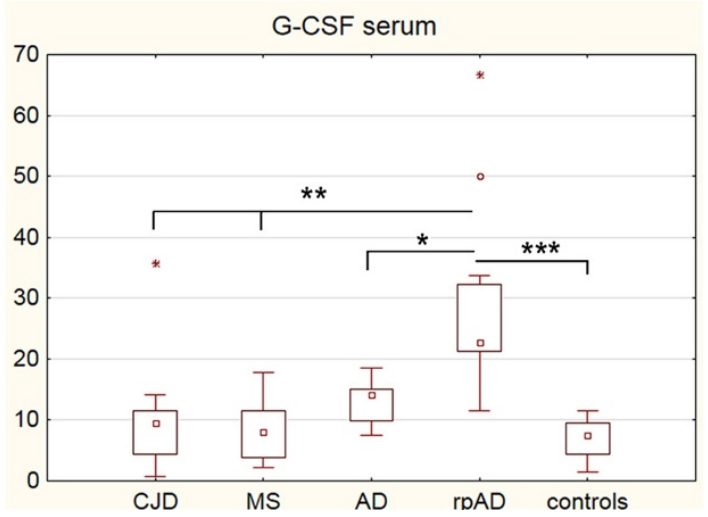

B

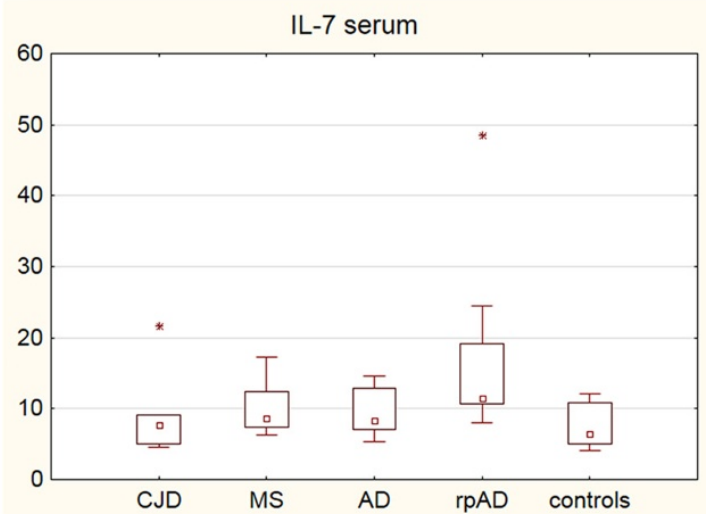

D

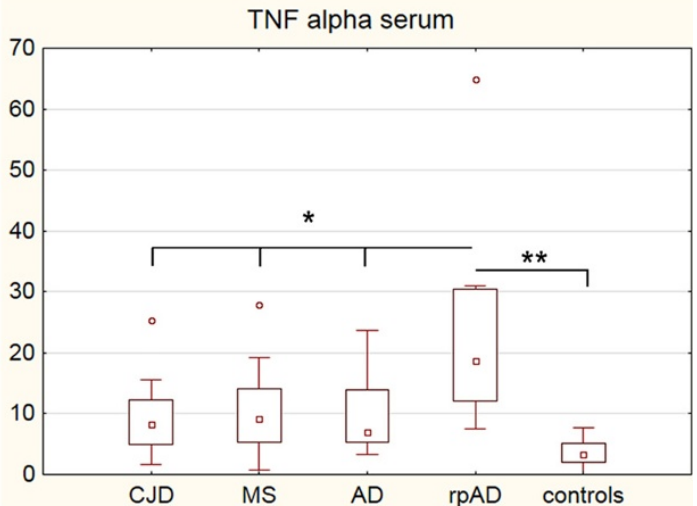

$\mathrm{F}$

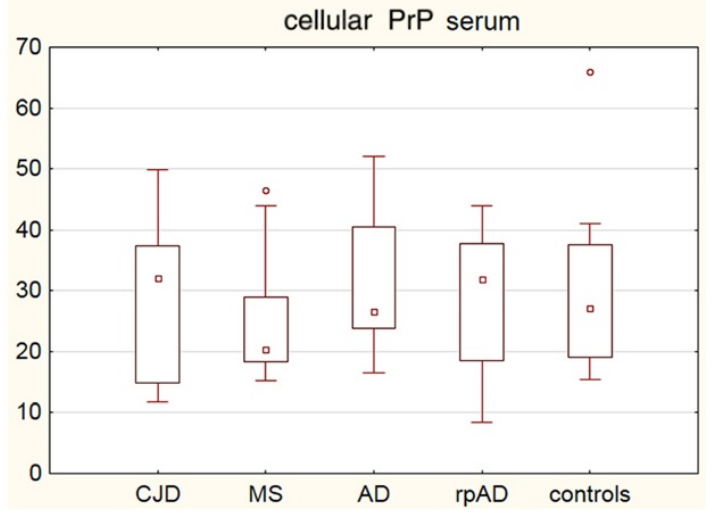

Figure 1 Different immune responses in the serum of patients with rapidly progressive dementia. (A-E) Profiling of cytokines (measured in $\mathrm{pg} / \mathrm{ml}$ ) in serum from Creutzfeldt-Jakob disease (CJD) $(n=12)$, multiple sclerosis (MS) $(n=12)$, Alzheimer's disease (AD) ( $n=20)$, a rapidly progressive form of $A D$ (rpAD) $(n=15)$ and control $(n=12)$ patients was performed using the Bio-Plex Pro human cytokine 17-plex assay. A significant distinction in rpAD patients was identified for IL-6, IL-13, TNF-a and G-CSF. (F) PrPC level in serum did not vary among groups. Columns represent means with SD. Statistics were performed by using the non-parametric Kruskal-Wallis test (+Tukey's post hoc tests). The number of stars indicates the significance level: one star $\left(^{*}\right)$ for $P<0.05$, two ${ }^{(*)}$ for $P<0.01$ and three $\left(^{* *}\right)$ for $P<0.001$. 


\section{Elevated chemokine levels in cerebrospinal fluid in patients with Alzheimer's disease and Creutzfeldt-Jakob disease}

The levels of a cytokine panel, consisting of 17 different cytokines, were measured in CSF samples from CJD, MS, AD, rpAD and control patients using the Bio-Plex Pro human cytokine 17-plex assay. In CSF, we observed significantly elevated levels of IL-8 und MCP in CJD and $\mathrm{AD}$ (MCP-1) patients compared to control donors (Figure 2A and B). Both cytokines are potent proinflammatory chemokines related to an innate immune response. The expression of IL-1 $\beta$, IL-2, IL-4, IL-5, IL-6, IL-7, IL-10, IL-12 (p70), IL-13, IL-17, G-CSF, GM-CSF, IFN- $\gamma$, MIP- $1 \beta$ and TNF- $\alpha$ was either not measurable or not significantly changed in the CSF of our patient cohort (data not shown).
Comparison of dementia marker profiles in the cerebrospinal fluid of patients with Alzheimer's disease or a rapidly progressive form of Alzheimer's disease

Levels of total Tau, p-Tau, $A \beta 1-40$ and $A \beta 1-42$ in the CSF of $\mathrm{AD}$ and rpAD patients were determined by ELISA. We ensured the stability of these biomarker proteins to defined short-term storage conditions [see Additional file 2]. Our data revealed that CSF dementia marker profiles, as well as the general $A \beta-40 / 42$ ratio, did not vary significantly between $A D$ and rpAD patients, suggesting an independent role of the immune system responses in rpAD (Figure 3A-E).

\section{Discussion}

Rapidly progressive dementia, in contrast to the more common forms of dementia, is a subset that follows an

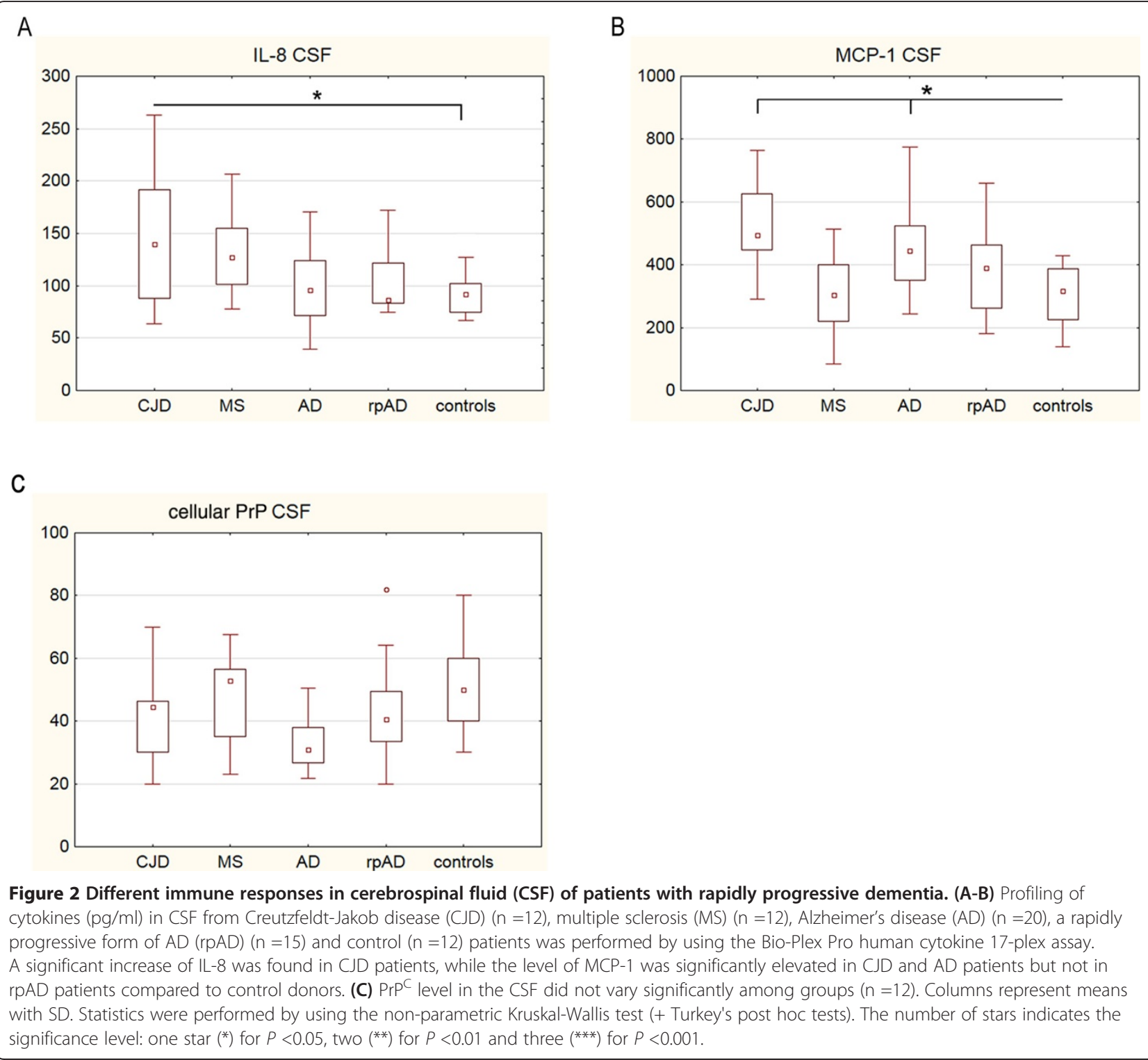


accelerated course of cognitive, behavioral and motor decline over a period of less than 2 years. An important cause is CJD or rpAD.

We aimed to understand the role of the immune system as a modifier of disease pathogenesis in $\mathrm{AD}$ with various progression rates.

Performing a multiplex analysis of 17 cytokines and chemokines in serum and CSF, we analyzed inflammatory profiles of rapidly progressive dementias such as CJD and rpAD (disease duration $<2$ years) in comparison to 'classical' $\mathrm{AD}$ as a form of dementia with a general disease duration of 7 to 20 years. Furthermore, we included patients with MS as a candidate disease for a chronic inflammatory CNS disease with neurodegeneration. Interestingly, we observed a characteristic proinflammatory cytokine response in rpAD patients, which was not obtained in the same way as in the classical AD patients. Several proinflammatory cytokines were elevated in the serum of rpAD patients, which may reflect a genuine systemic immune response to be causative for the rapidly progressive course in this $\mathrm{AD}$ subform.

\section{Proinflammatory immunomarkers are elevated in the} serum of patients who have a rapidly progressive form of Alzheimer's disease

RpAD was recently identified as representing a rapid subtype of $\mathrm{AD}$ [13]. In comparison to other dementias (AD or CJD), MS and controls, we observed an elevated level

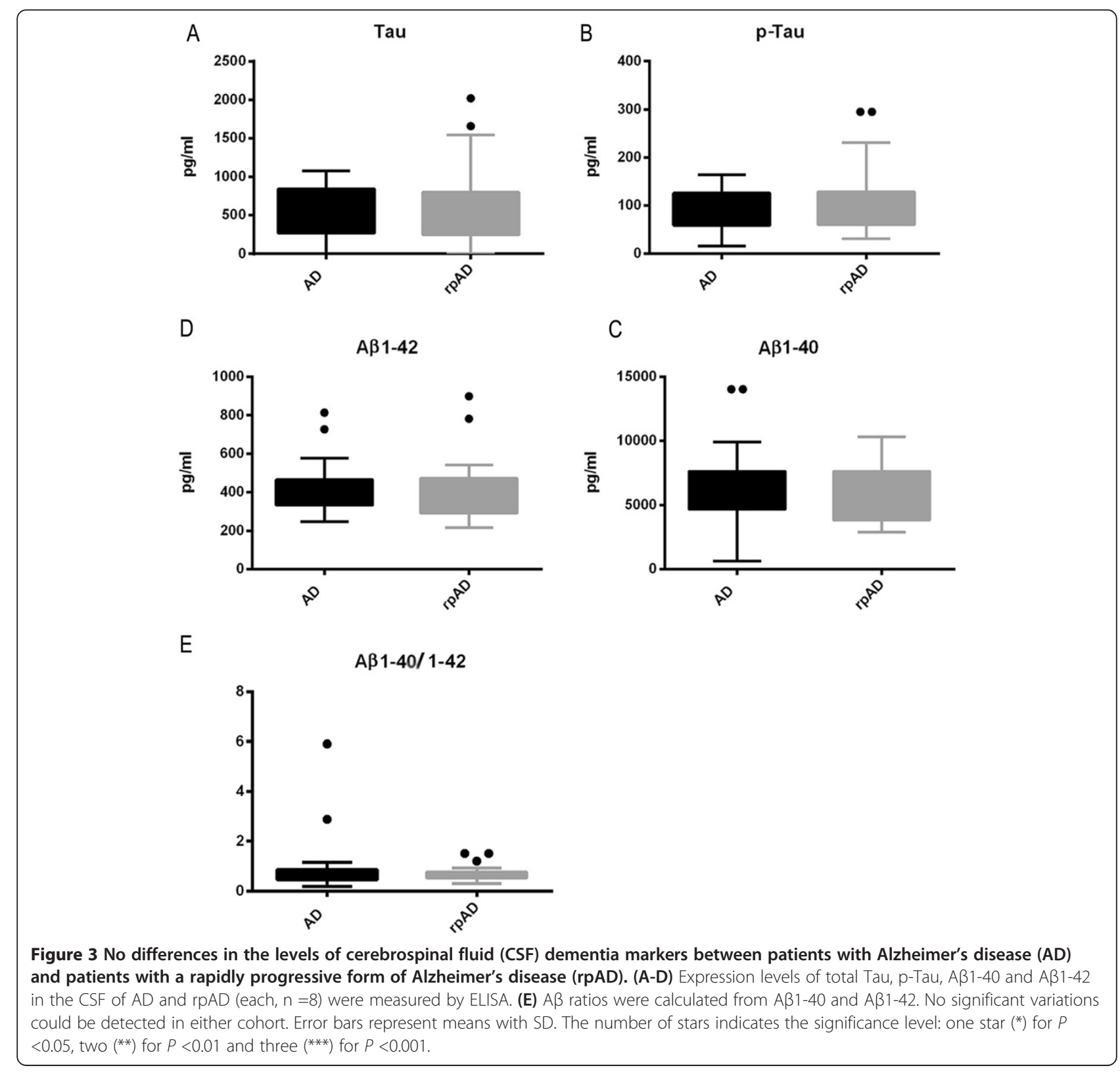


of proinflammatory cytokines (IL-6, IL-13, TNF- $\alpha$ and G-CSF) specifically in the serum of rpAD patients. This cytokine spectrum reflects both a Th1 and Th2 immune response. However, the spectrum weighs in favor of a proinflammatory immune activation. The level of $\operatorname{PrP}^{\mathrm{C}}$ did not vary significantly between $\mathrm{AD}$ and $\mathrm{rpAD}$ either in the serum or in the CSF, indicating that the increased immune response in rpAD occurs independently of $\operatorname{PrP}^{\mathrm{C}}$. This observation is in line with a previous study, which demonstrated that the $\operatorname{PrP}^{\mathrm{C}}$ level in CSF is not associated with the cognitive status of AD patients [21].

To our knowledge this is the first study providing an inflammatory profile for rpAD patients in comparison to $\mathrm{AD}$ patients. Findings of previous studies on $\mathrm{AD}$ patients are contradictory, leaving the debate of inflammatory marker in AD still open. While Licastro et al. [22] and Sun et al. [23] observed an increase inflammatory response in the blood of $\mathrm{AD}$ patients, other goups reported that immunological responses are not the major contributors to the pathogenesis of $\mathrm{AD}[24,25]$. This discrepancy may reflect different detections assays with different sensitivities or different patient numbers and characteristics.

Our finding might reflect a systemic immune activation in the rpAD group that did not present in the same way in MS, AD or CJD and control patients. It may be influential in the acceleration of the disease course in $\mathrm{AD}$, independent of the general phenomenon in rapidly progressive dementia pathogenesis because in CJD the immunomarkers were not elevated in the same way. This argument is supported by the finding that we do not see major differences among the CSF destruction markers Tau, $p$-Tau and $A \beta 1-40 /-42$ or between the $A \beta$ ratios in $\mathrm{AD}$ and rpAD patients.

Our findings may be helpful in explaining pathogenetic differences between $\mathrm{rpAD}$ and $\mathrm{AD}$.

\section{Elevated levels of IL-8 und MCP-1 in the cerebrospinal fluid of Creutzfeldt-Jakob disease and Alzheimer's disease patients}

Since CSF has been demonstrated to be a subanalyte for the detection of biomarkers in neurodegenerative dementia (both AD and CJD) [15] and has provided a better understanding of neurodegenerative brain diseases, we screened the CSF in patients with rapidly progressive dementias such as CJD or rpAD for inflammatory markers.

Interestingly, we found elevated levels of the chemokines IL- 8 and MCP-1 in the CSF of CJD patients and MCP-1 in the CSF of AD patients. As these markers are mostly involved in mechanisms of the innate immune response, they might represent an atypical neuroinflammatory response as reflected by microglia activation and astrogliosis in the neurodegenerative process. Previous studies on inflammatory markers in the CSF of AD patients are also conflicting. Most of the groups observed no marked differences between $\mathrm{AD}$ and the control group [25], which is in line with our findings. An increased level of $\mathrm{MCP}$ in $\mathrm{AD}$ patients was described in blood earlier [26].

From the rapidly progressive dementia group, IL- 8 and MCP-1 were only elevated in the CSF of CJD but not in rpAD patients, indicating a more disease-specific function independent from the course of the disease. Increased levels of IL-8 in the CSF of CJD patients are in line with a previously reported study using a regular ELISA [27].

Discrepancies, observed in results of divergent cytokine levels in the CSF and serum, are most likely related to the blood brain barrier, which separates the brain's immune system from the periphery. The blood brain barrier is partly responsible for the initial concept that the brain is an immune privileged site, with restricted passage of immune cells into the brain. It prevents the passage of large molecules from the blood into the brain parenchyma [28]. It is therefore assumed that the CSF directly mirrors pathological events in the central nervous system (CNS); thus cytokine regulations in serum reflect peripheral immune responses independendly from the CNS.

In conclusion, an understanding of the neuroinflammatory process in neurodegenerative dementias becomes more and more important, especially as it might reveal new insights into the pathogenesis of rapidly progressive forms of dementia (rpAD, CJD). Our major finding shows a unique immune response profile in the serum of the group of rpAD that was distinguishable from the other disease groups, especially 'classical' AD. Our results may indicate a systemic activation of the immune system in this AD subtype.

\section{Additional files}

Additional file 1: Statistical analysis of cytokine levels in CSF and serum. For all patient groups, mean and SD were shown for IL-6, IL-7, IL-8, IL-12, IL-13, MCP-1, MIP-1 beta, G-CSF and TNF-a.

Additional file 2: Stability of $A \beta 1-40, A \beta 1-42$, Tau and p-Tau 181 under defined storage conditions. CSF samples from AD patients ( $n=8$ ) were stored at $-80^{\circ} \mathrm{C}$, and incubated at $4^{\circ} \mathrm{C}$, as well as at room temperature (RT), for 7 days. Protein expression levels were determined by ELISA and calculated as percent of control samples at time point zero, defined as 100\%. No significant decrease in (A) A 1-40, (B) A 1-42, (C) Tau and (D) p-tau 181-level could be detected under these short-term storage conditions. Error bars represent means with SD. The number of stars indicates the significance level: one $\operatorname{star}\left({ }^{*}\right)$ for $P<0.05$, two $\left(^{* *}\right)$ for $P<0.01$ and three $\left.{ }^{(* *}\right)$ for $P<0.001$.

\section{Abbreviations}

Aß: amyloid beta; AD: Alzheimer's disease; CJD: Creutzfeldt-Jakob disease; CSF: cerebrospinal fluid; MS: multiple sclerosis; PrP: prion protein; rpAD: a rapidly progressive form of Alzheimer's disease.

\section{Competing interests}

The authors declare that they have no competing interests. 


\section{Authors' contributions}

KS designed the study, interpreted data, wrote the manuscript, provided samples (MS, controls), and performed statistical data analysis. MS wrote the manuscript, interpreted data, and performed experiments. EE performed experiments. CS provided samples (AD and rpAD). IZ interpreted data, wrote the manuscript, and provided samples (CJD). All authors read and approved the final manuscript.

\section{Acknowledgements}

The work was supported by a grant from the European Commission: Protecting the food chain from prions: shaping European priorities through basic and applied research (PRIORITY, NN222887) Project number: FP7KBBE-2007-2A and Neurodegenerative Disease Research (JPND - DEMTEST: Biomarker based diagnosis of rapidly progressive dementias-optimization of diagnostic protocols, 01ED1201A) as well as from the Alzheimer-ForschungsInitiative e.V. (AFI 12851). Moreover, we obtained funding from the Bundesministerium für Bildung und Forschung within the German Network for Degenerative Dementia (KNDD-2, 2012-2015, determinants for disease progression in AD, grant No.01G|1010C). arroyo572.

Received: 15 April 2014 Accepted: 24 September 2014 Published online: 15 October 2014

\section{References}

1. Lue LF, Rydel R, Brigham EF, Yang LB, Hampel H, Murphy GM Jr, Brachova L, Yan SD, Walker DG, Shen Y, Rogers J: Inflammatory repertoire of Alzheimer's disease and nondemented elderly microglia in vitro. Glia 2001, 35:72-79.

2. Rogers J, Lue LF: Microglial chemotaxis, activation, and phagocytosis of amyloid beta-peptide as linked phenomena in Alzheimer's disease. Neurochem Int 2001, 39:333-340.

3. Akiyama H, Barger S, Barnum S, Bradt B, Bauer J, Cole GM, Cooper NR, Eikelenboom P, Emmerling M, Fiebich BL, Finch CE, Frautschy S, Griffin WS, Hampel H, Hull M, Landreth G, Lue L, Mrak R, Mackenzie IR, McGeer PL, O'Banion MK, Pachter J, Pasinetti G, Plata-Salaman C, Rogers J, Rydel R, Shen Y, Streit W, Strohmeyer R, Tooyoma I, et al:: Inflammation and Alzheimer's disease. Neurobiol Aging 2000, 21:383-421.

4. Williams $A E$, Lucassen PJ, Ritchie D, Bruce M: PrP deposition, microglial activation and neuronal apoptosis in murine scrapie. Exp Neurol 1997, 144:433-438.

5. Hoozemans JJM, Rozemuller AJM, Janssen I, De Groot CJA, Veerhuis R, Eikelenboom P: Cyclooxygenase expression in microglia and neurons in Alzheimer's disease and control brains. Acta Neuropathol (Berl) 2001, 101:2-8.

6. Parkin ET, Watt NT, Hussain I, Eckman EA, Eckman CB, Manson JC, Baybutt HN, Turner AJ, Hooper NM: Cellular prion protein regulates $\beta$-secretase cleavage of the Alzheimer's amyloid precursor protein. Proc Natl Acad Sci U S A 2007, 104:11062-11067.

7. Laurén J, Gimbel DA, Nygaard HB, Gilbert JW, Strittmatter SM: Cellular prion protein mediates impairment of synaptic plasticity by amyloidbeta oligomers. Nature 2009, 457:1128-1132.

8. Schmitz M, Wulf K, Signore SC, Schulz-Schaeffer WJ, Kermer P, Bähr M, Wouters FS, Zafar S, Zerr I: Impact of the Cellular Prion Protein on Amyloid- $\beta$ and 3PO-Tau Processing. J Alzheimers Dis 2013, 38:551-565.

9. Tsutsui S, Hahn JN, Johnson TA, Ali Z, Jirik FR: Absence of the cellular prion protein exacerbates and prolongs neuroinflammation in experimental autoimmune encephalomyelitis. Am J Patho/ 2008, 173:1029-1041.

10. Hu W, Nessler S, Hemmer B, Eagar TN, Kane LP, Leliveld SR, Müller-Schiffmann A, Gocke AR, Lovett-Racke A, Ben LH, Hussain RZ, Breil A, Elliott JL, Puttaparthi K, Cravens PD, Singh MP, Petsch B, Stitz L, Racke MK, Korth C, Stüve O: Pharmacological prion protein silencing accelerates central nervous system autoimmune disease via T cell receptor signalling. Brain 2010, 133:375-388.

11. Zerr I, Kallenberg K, Summers DM, Romero C, Taratuto A, Heinenmann U, Breithaupt M, Meissner B, Ladogana A, Schuur M, Haik S, Collins SJ, Jansen GH, Stokin GB, Pimentel J, Hewer E, Collie D, Smith P, Roberts H, Brandel JB, van Duijn C, Pocchiari M, Begue C, Cras P, Will RG, Sanchez-Juan P: Updated clinical diagnostic criteria for sporadic Creutzfeldt-Jakob disease. Brain 2009, 132:2659-2668.

12. Parchi P, Giese A, Capellari S, Brown P, Schulz-Schaeffer W, Windl O, Zerr I, Budka H, Kopp N, Piccardo P, Poser S, Rojiani A, Streichemberger N, Julien J, Vital C, Ghetti B, Gambetti P, Kretzschmar H: Classification of sporadic
Creutzfeldt-Jakob disease based on molecular and phenotypic analysis of 300 subjects. Ann Neurol 1999, 46:224-233.

13. Schmidt C, Haïk S, Satoh K, Rábano A, Martinez-Martin P, Roeber S, Zerr I: Rapidly progressive Alzheimer's disease: a multicenter update. J Alzheimers Dis 2012, 29:1-6.

14. WHO: Human transmissible spongiform encephalopathies. Wkly Epidemiol Rec 1998, 47:361-365.

15. Zerr I, Pocchiari M, Collins S, Brandel JP, de Pedro CJ, Knight RS, Bernheimer H, Cardone F, Delasnerie-Lauprêtre N, Cuadrado Corrales N, Ladogana A, Bodemer M, Fletcher A, Awan T, Ruiz Bremón A, Budka H, Laplanche JL, Will RG, Poser S: Analysis of EEG and CSF 14-3-3 proteins as aids to the diagnosis of Creutzfeldt-Jakob disease. Neurology 2000, 55:811-815.

16. Dubois B, Feldman HH, Jacova C, Dekosky ST, Barberger-Gateau P, Cummings J, Delacourte A, Galasko D, Gauthier S, Jicha G, Meguro K, O'brien J, Pasquier F, Robert P, Rossor M, Salloway S, Stern Y, Visser PJ, Scheltens P: Research criteria for the diagnosis of Alzheimer's disease: revising the NINCDS-ADRDA criteria. Lancet Neurol 2007, 6:734-746.

17. Schmidt C, Wolff M, Weitz M, Bartlau T, Korth C, Zerr I: Rapidly progressive Alzheimer disease. Arch Neurol 2011, 68:1124-1130.

18. Polman CH, Reingold SC, Banwell B, Clanet M, Cohen JA, Filippi M Fujihara K, Havrdova E, Hutchinson M, Kappos L, Lublin FD, Montalban X O'Connor P, Sandberg-Wollheim M, Thompson AJ, Waubant E, Weinshenker B, Wolinsky JS: Diagnostic criteria for multiple sclerosis: 2010 revisions to the McDonald criteria. Ann Neurol 2011, 69:292-302

19. Schmitz M, Lüllmann K, Zafar S, Ebert E, Wohlhage M, Oikonomou P, Schlomm M, Mitrova E, Beekes M, Zerr I: Association of prion protein genotype and scrapie prion protein type with cellular prion protein charge isoform profiles in cerebrospinal fluid of humans with sporadic of familial prion diseases. Neurobiol Aging 2014, 35:1177-1188.

20. Schmitz M, Schlomm M, Hasan B, Beekes M, Mitrova E, Korth C, Breil A, Carimalo J, Gawinecka J, Varges D, Zerr I: Codon 129 polymorphism and the E200K mutation do not affect the cellular prion protein isoform composition in the cerebrospinal fluid from patients with CreutzfeldtJakob disease. Eur J Neurosci 2010, 31:2024-2031.

21. Schmidt C, Artjomova S, Hoeschel M, Zerr I: CSF prion protein concentration and cognition in patients with Alzheimer disease. Prion 2013, 7:229-234.

22. Licastro F, Pedrini S, Caputo L, Annoni G, Davis LJ, Ferri C, Casadei V, Grimaldi LM: Increased plasma levels of interleukin-1, interleukin- 6 and alpha-1- antichymotrypsin in patients with Alzheimer's disease: peripheral inflammation or signals from the brain? J Neuroimmunol 2000, 103:97-102.

23. Sun $Y X$, Minthon $L$, Wallmark A, Warkentin S, Blennow $K$, Janciauskiene $S$ : Inflammatorymarkers in matched plasma and cerebrospinal fluid from patients with Alzheimer's disease. Dement Geriatr Cogn Disord 2003, 16:136-144.

24. Lanzrein AS, Johnston CM, Perry VH, Jobst KA, King EM, Smith AD: Longitudinal study of inflammatory factors in serum, cerebrospinal fluid, and brain tissue in Alzheimer disease: interleukin-1 beta, interleukin- 6 , interleukin-1 receptor antagonist, tumor necrosis factor-alpha, the soluble tumor necrosis factor receptors I and II, and alpha1antichymotrypsin. Alzheimer Dis Assoc Disord 1998, 12:215-227.

25. Choi C, Jeong JH, Jang JS, Choi K, Lee J, Kwon J, Choi KG, Lee JS, Kang SW: Multiplex analysis of cytokines in the serum and cerebrospinal fluid of patients with Alzheimer's disease by color-coded bead technology. J Clin Neurol 2008, 4:84-88.

26. Galimberti D, Schoonenboom N, Scarpini E, Scheltens P: Chemokines in serum and cerebrospinal fluid of Alzheimer's disease patients. Ann Neurol 2003, 53:547-548

27. Stoeck K, Bodemer M, Zerr I: Pro- and anti-inflammatory cytokines in the CSF of patients with Creutzfeldt-Jakob disease. J Neuroimmunol 2006, 172:175-181.

28. Marques F, Sousa JC, Sousa N, Palha JA: Blood-brain-barriers in aging and in Alzheimer's disease. Mol Neurodegener 2013, 8:38.

doi:10.1186/s12974-014-0170-y

Cite this article as: Stoeck et al:: Immune responses in rapidly progressive dementia: a comparative study of neuroinflammatory markers in Creutzfeldt-Jakob disease, Alzheimer's disease and multiple sclerosis. Journal of Neuroinflammation 2014 11:170. 